\title{
Asymmetric heterogeneous catalytic hydrogenation; is it a useful tool for the synthetic organic chemist?
}

\author{
Antal Tungler, ${ }^{* a}$ Éva Sípos, ${ }^{b}$ and Viktor Háda ${ }^{c}$ \\ ${ }^{a}$ Budapest University of Technology and Economics, \\ Department of Chemical Technology 1521 Budapest Hungary \\ ${ }^{b}$ EGIS Rt, Budapest \\ ${ }^{c}$ Richter Gedeon Rt, Budapest \\ E-mail: atungler@mail.bme.hu
}

\section{Dedicated to Professor Dr. Sándor Antus on the occasion of his $60^{\text {th }}$ birthday}

(received 23 Dec 03; accepted 17 Apr 04; published on the web 21 Apr 04)

\begin{abstract}
The evaluation of different asymmetric hydrogenation methods is presented: the use of anchored chiral transition metal complexes modified metal catalysts and diastereoselective reactions, partly with chiral synthons. Recent results and perspectives are summarized.
\end{abstract}

Keywords: Catalytic hydrogenation, asymmetric synthesis, enantioselectivity, diastereoselectivity, optically active products, chiral modification, anchoring, metal catalysts

\section{Contents}

Introduction

1. Enantioselective reductions

1.1 Heterogenized transition metal complexes

1.2 Modified metal catalysts

1.2.1. Nickel catalysts

1.2.2. Platinum catalysts

1.2.3. Palladium catalysts

2. Diastereoselective reactions

2.1 Reactions of achiral compounds

2.2 Reactions of chiral compounds

3. Conclusions 


\section{Introduction}

Liquid phase catalytic hydrogenation became in the last hundred years a beneficial method among organic chemical processes, applied both in laboratory and in industry. ${ }^{1-7} \mathrm{~A}$ recent challenge has been the preparation of stereoisomeric compounds, especially that of the optically active compounds even in large scale. The market of optically active drug molecules has been growing rapidly. ${ }^{8}$ The possible reduction methods serving this need can be: use of optically active reducing agents, optically active transition metal complexes in homogeneous phase, heterogenized metal complexes or modified metal catalysts in heterogeneous phase, optically active synthons in diastereoselective heterogeneous catalytic hydrogenation, biochemical, namely enzyme catalysis.

The advantages and disadvantages of these methods are well known, however the practical usefulness of heterogeneous catalytic reactions is obvious. The ease of separation is characteristic of some transition metal complex catalysed reactions also, which apply water soluble ligands, anchored or encapsulated complexes.

The competition between homogeneous and heterogeneous catalytic asymmetric hydrogenation began more than forty years ago when Izumi and his co-workers discovered the enantioselective hydrogenation of $\beta$-ketoesters with tartaric acid modified Raney-nickel. ${ }^{9}$ The most significant stages of these processes are the following: ${ }^{10}$

Homogeneous reactions of complexes

- First attempt: $1966 \mathrm{Cu}^{\text {II }}$ catalyzed addition of diazoacetic acid ester to styrene, $\sim 10 \%$ ee

- $\quad$ First good enantioselectivity: 1972, with DIOP ligand

- First (published) large scale industrial application: 1991 Takasago menthol process

- 1996 Novartis-Dual herbicide production, $\mathrm{C}=\mathrm{N}$ enantioselective reduction

- $\quad$ Nobel prize 2001: Knowles, Noyori, Sharpless

Heterogeneous reactions

- First attempt: 1922 bromine addition on cinnamic acid by $\mathrm{ZnO}$ /fructose Erlenmeyer

- $\quad$ First good enantioselectivity: $1963 \beta$-ketoester hydrogenation with tartaric acid modified Raney-nickel

- Best system: $1976 \alpha$-ketoester hydrogenation with cinchonidine modified Pt-on-alumina catalyst

- First $\mathrm{C}=\mathrm{C}$ hydrogenation with high ee: 2002 , hydrogenation of pyrones with cinchonidine modified Pd catalyst. ${ }^{11}$

The unequal competition is still going on, the number of publications characterises the situation, papers about asymmetric homogeneous catalysed hydrogenations are at least ten times as much as those about heterogeneous asymmetric hydrogenations. The latter papers however indicate a firm development, not only in numbers but in the scope and efficiency of this research. 
Twenty years ago, when the research of heterogeneous asymmetric hydrogenation began at our institution, the other groups all over the world working on the same field could be identified easily, nowadays subsequent teams appear on this scene. The researchers use the most sophisticated techniques and molecular modelling to explore the surface phenomena during asymmetric hydrogenations ${ }^{12-17}$. As a consequence, a breakthrough can be expected, first in understanding of the mechanism, later in the efficiency of enantioselective heterogeneous catalysed hydrogenations.

In recent years beside the large number of original papers, several reviews ${ }^{18-41}$ were published about these topics too, with rather different intentions, some of them are detailed and orientating.

In the present paper, in order to extend the former reviews, the different methods of asymmetric heterogeneous catalytic hydrogenation are outlined and compared with each other from the point of view of synthetic utilisation.

\section{Enantioselective reductions}

\subsection{Heterogenized transition metal complexes}

The two known methods of heterogenization are summarized well in the books of De Vos et al. ${ }^{26}$ and of Cornils and Herrmann: ${ }^{33}$ anchoring and phase variation. During anchoring the catalyst is bound by chemical methods to the surface of a support matrix, in phase variation the catalyst is dissolved in water, in a fluorinated solvent or in non-aqueous ionic liquid, which can be separated from the solvent containing the substrate and the product.

The so-called biphasic catalysis started with the synthesis of water-soluble ligands, this solubility was achieved by introducing highly polar substituents into the phosphine ligands, like $-\mathrm{SO}_{3} \mathrm{H},-\mathrm{COOH},-\mathrm{OH},-\mathrm{NH}_{2}$. The best known example of aqueous catalysis is the $\mathrm{Rh}$ catalysed oxo-process. ${ }^{42}$ Water soluble ligands were also applied in hydrogenation reactions, ${ }^{43}$ numerous studies were devoted to the enantioselective hydrogenation. ${ }^{44-58}$ Optically active amino acids were prepared from amidoacrylic acid and amidocinnamic acid precursors, usually with lower reaction rates and enantiomeric excesses than in the counterpart homogeneous reactions. A recent review of Dwars et $\mathrm{al}^{34}$ reports an enhancement of enantioselectivity and activity in the hydrogenation of amino acid precursors in microheterogeneous (aqueous micellar) systems.

Immobilisation is feasible through fixation to a support via covalent bonding, these supports can be polymers, inorganic materials. Fixation can be made also by ionic bonding and entrapping in porous materials. A recent method of immobilization was carried out via supported liquids, the catalyst is dissolved in organic low vapour pressure solvents (Supported Liquid Phase Catalysis) or in water (Supported Aqueous Phase Catalysis) and from this solution a thin film is formed on the surface of an appropriate support. ${ }^{33}$ Practical application of such catalysts is not known so far, the reasons could be the decreased activity and selectivity, which is often accompanied by the leaching of the metal or the complex. However recent results, reviewed by Crudden et al., ${ }^{36}$ 
show the importance of the application of highly ordered, silica based mesoporous materials, such as MCM-41, SBA-15 and FSM-16, for grafting of phosphines, used as catalysts in enantioselective hydrogenations too.

It is always debatable, how the patent literature can be treated in a review of scientific papers, however this information gives an insight into what is going on in the laboratories devoted to industrial research. The researchers of Institut für Angewandte Chemie Berlin-Adlershof issued a patent application about transition metal complex catalyst heterogenization with a surfactant to an ionic polymer. ${ }^{59} \mathrm{~A}$ Ru-BINAP catalyst solution was added to the solution of decanephosphonic acid and $\mathrm{NaOH}$, and the above mixture was added to the solution of poly(diallyldimethylammonium chloride), this viscous liquid was deposited to a polypropylene plate, which was dried and beads were formed from it. The catalysts prepared this way, were used in the hydrogenation of itaconic acid, with 1:1,1 substrate:catalyst ratio (!!). The conversion at $60^{\circ} \mathrm{C}$ and 20 bar after two hours was $100 \%$, the ee was $89 \%$.

Tanielyan and Augustine filed two patent applications and received patents ${ }^{60,61}$ for a catalyst, comprising a support, an anchoring agent as a heteropolyacid or anion and a metal complex. The novelty of this anchoring method is that the heteropolyacid binds together the support and the metal of the complex so that no modification of the chiral ligand is needed. They presented some of their results at ORCS conferences ${ }^{62-66}$ about enantioselective hydrogenations. Where the active species are well known $\mathrm{Rh}$ or Ru complexes immobilized on supports and have been used in the reduction of amino acid precursors and itaconic acid. If the activity and enantioselectivity data are, however comparable with that of the same homogeneous complexes, a crucial question is the leaching. The authors did not convince the scientific community about the synthetic value of their catalyst, which is indicated by the lack of citation of their work in papers, reviews and books.

\subsection{Modified metal catalysts}

Among the attempts for preparing asymmetric heterogeneous catalysts the most successful was the modification with optically active compounds, these modifiers influenced the selectivity and activity of the catalyst by adding them to the catalyst or to the reaction mixture. ${ }^{67,68}$ These modified catalysts are very specific with respect to the substrate, this means, that the combination of the catalytically active metal and the modifier ensures the enantioselectivity only at a small group of substrates. The most effective heterogeneous catalytic hydrogenating systems are the Ni-tartaric acid, ${ }^{69-74}$ Pt-cinchona alkaloids, Pd-cinchona alkaloids and vinca alkaloids. ${ }^{75-77}$ (Scheme 1)

In these catalysts the source of chirality is an organic compound, which adsorbs strongly on the surface of the catalyst and creates a chiral environment for the hydrogenation. The substrates are in interaction simultaneously with the catalyst and the modifier, so give optically active product, through diastereomeric transition surface species. ${ }^{78}$ 


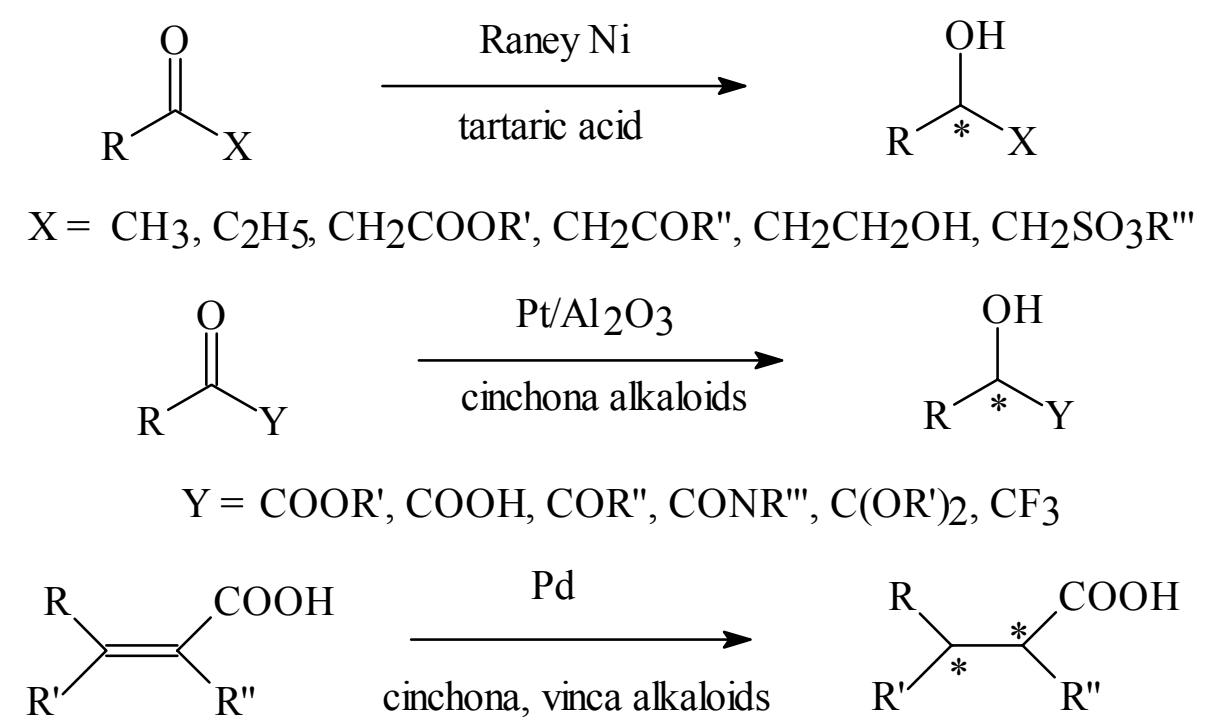

Scheme 1. Heterogeneous catalytic enantioselective hydrogenations. (R, R', R', are alkyl, aryl or hydrogen).

\subsubsection{Nickel catalysts}

A Ni-tartaric acid catalyst was used for the hydrogenation of $\beta$-ketoesters, that of in $\beta$ position functionalised ketones, and of 2-, and 3-alkanones. The Pt-cinchona catalysts are effective in the hydrogenation of $\alpha$-functionalised ketones, where the substituent has electron-withdrawing effect, the modified Pd catalysts can be applied for the reduction of olefins, with substituents as an acidic group or rich in electrons.

The modified $\mathrm{Ni}$ catalyst is prepared rather simply, the freshly activated catalyst is impregnated with the solution of tartaric acid and co-modifier $\mathrm{NaBr}$, which serves for poisoning of the racemic hydrogenation sites. The modified catalyst recognises the re and si face of the substrate and allows the dissociated hydrogen to attack the side facing the catalyst surface. ${ }^{72}$

Since the discovery of the so-called Izumi catalyst, several commercialised processes were developed, which utilised this hydrogenation: the reduction of methyl 2-methyl-oxobutirate, ${ }^{79}$ methyl acetoacetate, ${ }^{80} 3$-keto acids of 10-16 carbon atoms, ${ }^{81,82}$ the latter one is a development of Hoffman-La-Roche, aimed at the preparation of the intermediate of tetrahydrolipstatine with complete conversion and $90 \%$ e.e.

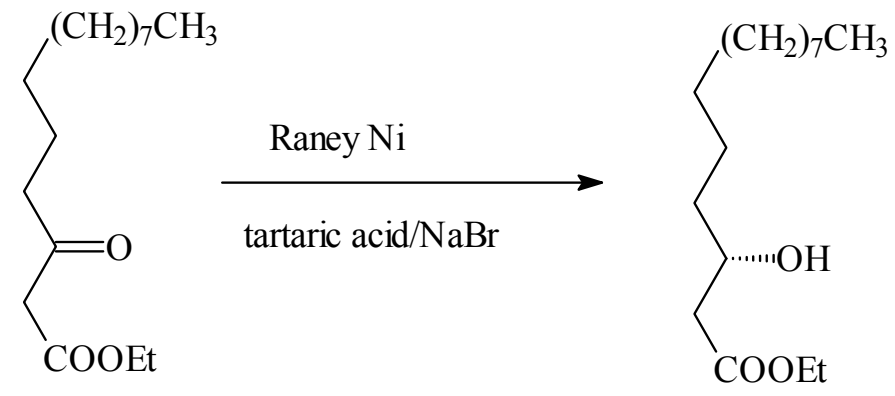

Scheme 2. Intermediate of a lipase inhibiting agent. 


\subsubsection{Platinum catalysts}

The Pt-cinchona system for the hydrogenation of $\alpha$-keto ester hydrogenation was discovered in 1979 by Orito and his co-workers. ${ }^{83-86}$ The chiral modification was carried out by simply adding cinchona alkaloids to the catalyst or even better, to the reaction mixture. The two most frequently applied alkaloids are cinchonidine and its quasi-enantiomer cinchonine, the former induces the formation of $(R)$-lactate in excess, the other that of the $(S)$-lactate.

Since the first application there was significant progress both in understanding of the mechanism of enantiodifferentiation and in the extension of the scope of this reaction, ${ }^{87-89}$ see Table 1.

Table 1. Hydrogenation of various ketones with cinchona modified $\mathrm{Pt} / \mathrm{Al}_{2} \mathrm{O}_{3}$ catalyst

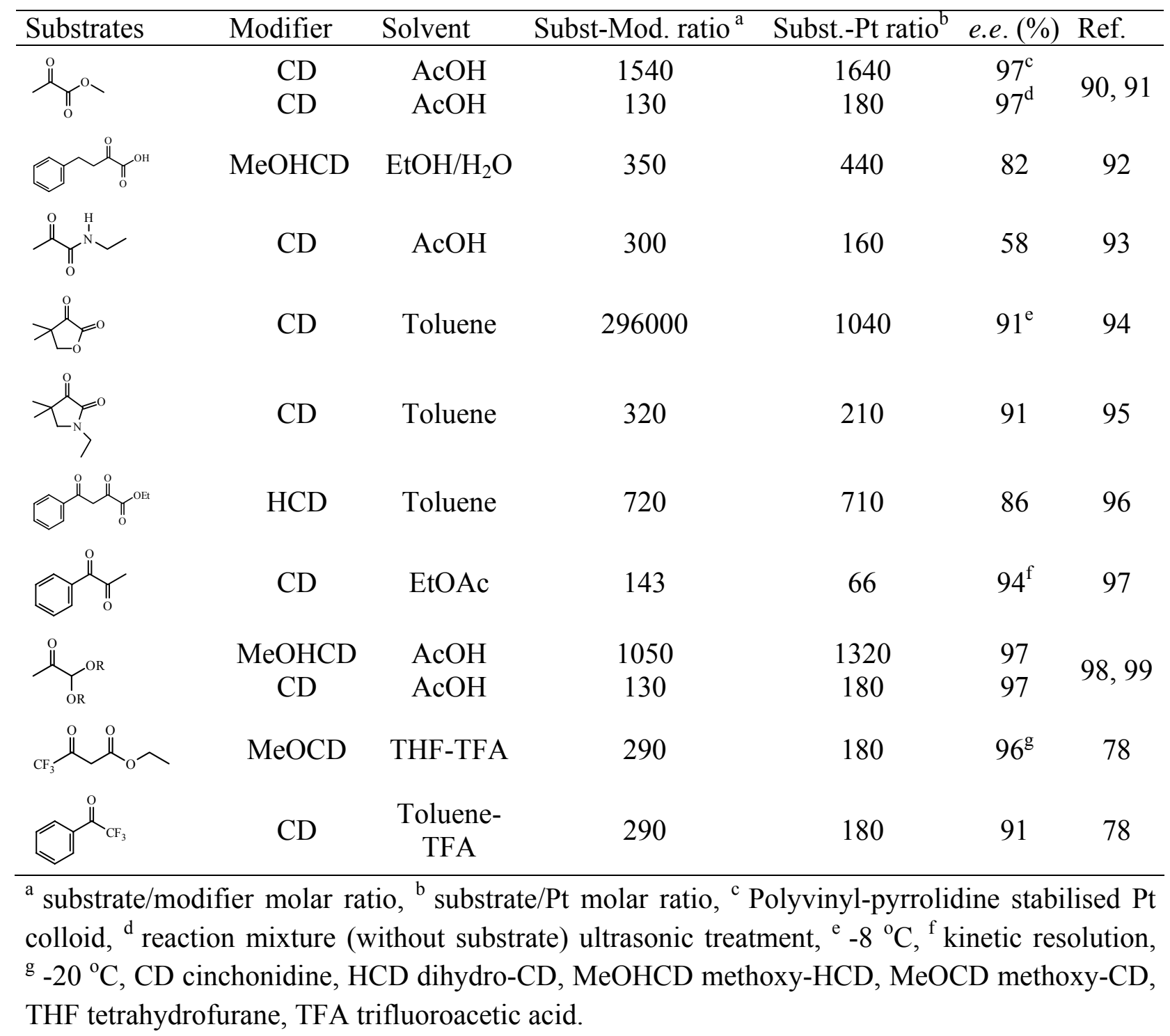


Among the optimized conditions the characteristic substrate/modifier ratio is between 1501800, which demonstrates the effective chiral multiplication. In the hydrogenation of ketopantolactone even much larger ratio (296000) was sufficient for the best e.e. The small catalyst and modifier concentrations require the careful purification of the substrate and the solvent.

The crucial characteristics of a good modifier are the following:

-a condensed aromatic part for anchoring on the metal surface,

-a stereogenic center determining the direction of enantioselection,

-a secondary or tertiary nitrogen in rigid, chiral environment, which can interact with the substrate, primarily through its carbonyl group.

The role of hydroxy group in cinchonidine is complex, in some cases it is necessary for the bidentate interaction with the substrate, in other cases it has no function.

The hydrogenation of $\alpha$-ketoesters gained industrial application in the preparation of benazepril, of an ACE inhibition agent, ${ }^{41}$ formerly the reduction of the keto-ester, later that of the diketoester was the key enantioselective step.

\subsubsection{Palladium catalysts}

The first $\mathrm{Pd}$ catalysed asymmetric hydrogenations of a $\mathrm{C}=\mathrm{C}$ bond were the not reproducible experiments with $\mathrm{Pd}$ on silk fibroin and on optically active quartz. ${ }^{100,101}$ More successful were the chirally modified $\mathrm{Pd}$ catalysts used in the hydrogenation of olefins possessing an electronrich or acidic functional group (scheme 1). ${ }^{87,102-107}$

The best modifiers are natural or synthetic alkaloids (scheme 3).

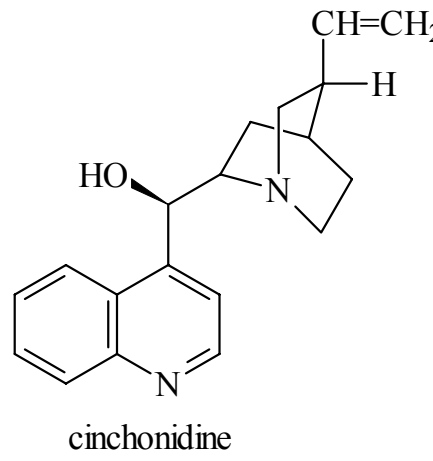

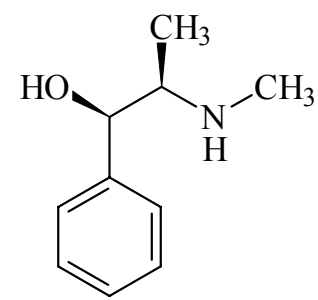

(-)-pseudo-ephedrine

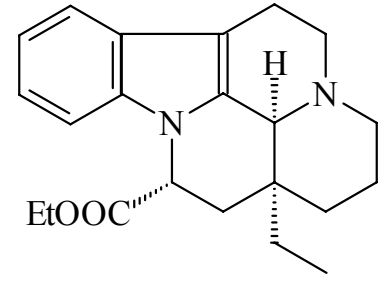

(-)-dihydroapovincaminic acid ethyl ester

Scheme 3. Chiral modifiers for hydrogenation.

Efficient modification of $\mathrm{Pd}$ requires markedly higher modifier/substrate ratio than that of for Pt. The necessary high modifier concentration leads to significant rate deceleration compared to the racemic reaction carried out in the absence of the modifier.

The enantioselective hydrogenation of $\alpha, \beta$-unsaturated carboxylic acids is widely studied, because the products of those processes are important intermediates in the synthesis of antiinflammatory agents, such as naproxen and ibuprofen. ${ }^{108-110}$ Rhodium and ruthenium complexes 
were developed for the homogeneous phase hydrogenations producing the saturated acids in excellent enantioselectivity (e.e. $\sim 99 \%) .{ }^{33,110,111}$ The solid catalysts however can be more beneficial due to their technological and economic advantages. The cinchonidine modified supported Pd is a useful solid catalyst in the enantioselective hydrogenation of $\alpha, \beta$-unsaturated carboxylic acids. ${ }^{105}$ The enantioselectivity strongly depends on the structure of the acid (scheme 4). ${ }^{112-114}$

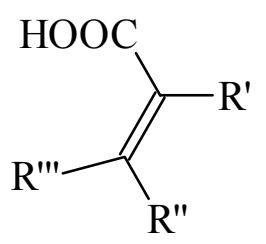

$\begin{array}{llll}\text { R' } & \text { R" } & \text { R'" } & \text { ee\% } \\ \mathrm{Et} & \mathrm{H} & \mathrm{H} & 20 \\ \mathrm{Me} & \mathrm{Me} & \mathrm{H} & 47 \\ \mathrm{Me} & \mathrm{Et} & \mathrm{H} & 52 \\ \mathrm{Bu} & \mathrm{H} & \mathrm{H} & 20 \\ \mathrm{Pr} & \mathrm{Me} & \mathrm{H} & 53 \\ \mathrm{Ph} & \mathrm{Ph} & \mathrm{H} & 72\end{array}$

Scheme 4. Enantioselective hydrogenation of $\alpha, \beta$-unsaturated acids.

According to Baiker and his co-workers the feasible explanation for the differences is the double bond migration in the substrate. ${ }^{115}$ The cinchona-modified Pd affords good enantioselectivity only if isomerization is slow (internal double bond in the substrate), or this competing reaction is not possible at all (diphenyl substituted alkenoic acid).

Using different cinchonidine derivatives, it was realized that the substrate-modifier interaction involves both the quinuclidine $\mathrm{N}$ and the $\mathrm{OH}$ group of cinchonidine. ${ }^{116,117}$ Another example for the use of cinchonidine-modified Pd is the preparation of ethyl nipecotinate from ethyl nicotinate in a two step procedure (scheme 5). ${ }^{118}$

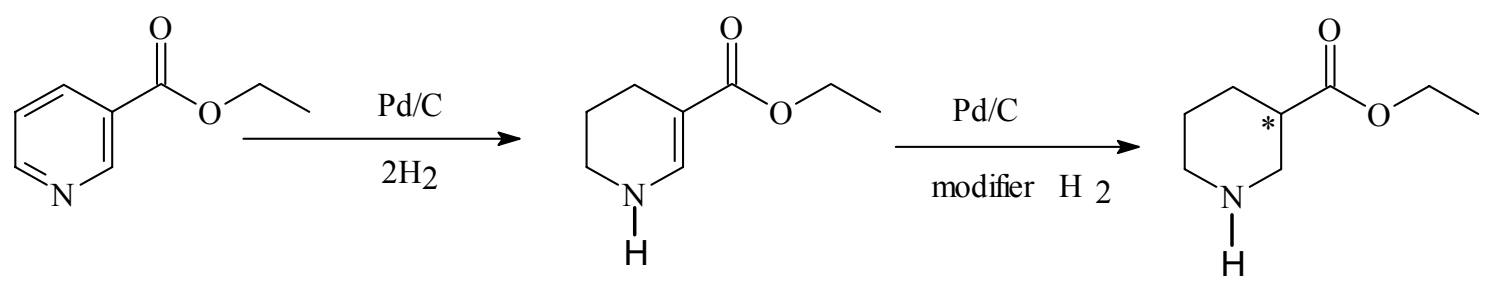

Scheme 5. Asymmetric hydrogenation of ethyl nicotinate.

The best e.e. of $24 \%$ at $10 \%$ conversion was achieved with $\mathrm{Pd} / \mathrm{TiO}_{2}$ and cinchonidine in $\mathrm{DMF} / \mathrm{H}_{2} \mathrm{O} 1 / 1$ with trace of acetic acid. This was the first case that one could hydrogenate an $\alpha, \beta$-unsaturated ester with significant e.e. using a chirally modified heterogeneous metal catalyst. 
Muzart and his co-workers used ephedrine as chiral modifier or auxiliary, which provided $19-36 \%$ e.e. in the enantioselective hydrogenation of some bicyclic $\alpha, \beta$-unsaturated indanone and tetralone derivatives (Scheme 6). ${ }^{119}$

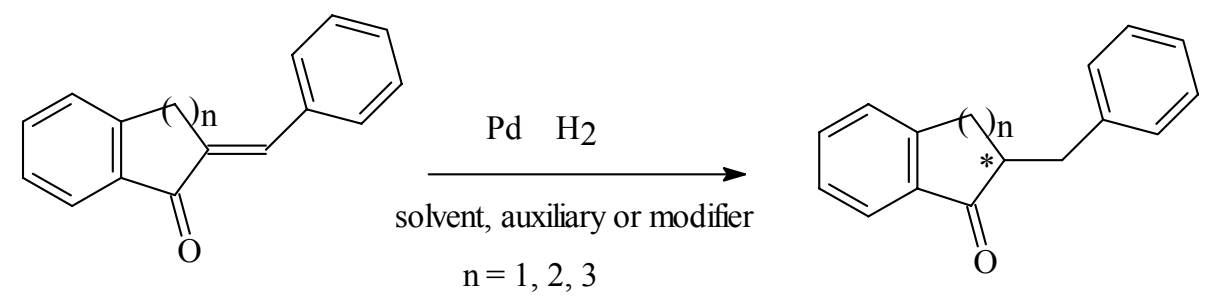

Scheme 6. Asymmetric hydrogenation of $\alpha, \beta$-unsaturated exocyclic ketones.

These exocyclic $\alpha, \beta$-unsaturated ketones can be reduced to the corresponding optically active saturated ketones in the presence of cinchona alkaloids ${ }^{120}$ over $\mathrm{Pd}$ catalysts. The enantioselectivity is strongly dependent on the solvent and the catalyst. The most efficient system was palladium black, cinchonidine modifier in toluene in the hydrogenation of the $(E)-2$ benzylidene-1-benzosuberone (e.e. 53.7\%). The optimal amount of modifier was $5 \% \mathrm{w} / \mathrm{w}$ with respect to the catalyst in this reaction.

Under the same conditions, the enantioselectivity was much lower for the five-, and sixmembered ring containing compounds. These significant differences between the enantioselectivity values can be attributed to the different rigidity and associate-forming ability of the substrate molecules. ${ }^{121}$

Another thoroughly investigated reaction over $\mathrm{Pd}$ is the hydrogenation of $\alpha, \beta$-unsaturated endocyclic ketones. A vinca alkaloid, the (-)-dihydroapovincaminic acid ethyl ester ((-)-DHVIN) was found to be an effective modifier in the hydrogenation of the $\mathrm{C}=\mathrm{C}$ bond of isophorone ${ }^{122}$ affording 55\% e.e. of the corresponding saturated ketone (Scheme 7). Cinchona alkaloids were moderately effective ( $20 \%$ e.e. $)$

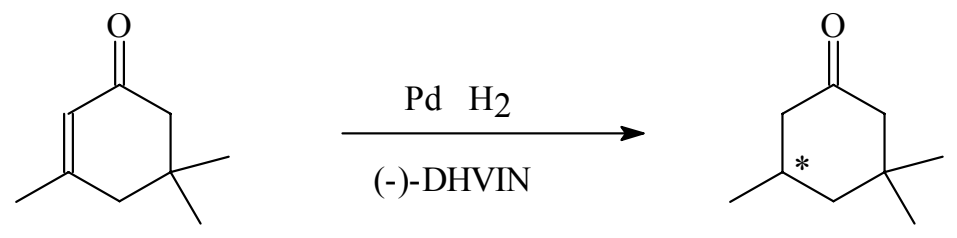

Scheme 7. Enantioselective hydrogenation of isophorone.

An important new application of cinchona modified $\mathrm{Pd}$ is the enantioselective hydrogenation of 4-alkoxy- and 4-methyl- derivatives of 2-pyrone. ${ }^{123}$ These studies demonstrate that the potential of chirally modified $\mathrm{Pd}$ is much broader than has been commonly considered and its efficiency is comparable with those of Pt-cinchona and Ni-tartarate systems. ${ }^{124}$ The asymmetric hydrogenation of substituted 2-pyrones has gained increasing interest in pharmaceutical chemistry, due to the importance of the structure of 2-pyrone and its partially hydrogenated derivatives in natural and synthetic biologically active compounds. Hydrogenation of pseudo- 
aromatic compound 4-hydroxy-6-methyl-2-pyrone (1a) (scheme 8) resulted in the $(S)$ enantiomer of the corresponding dihydropyrone (2a) with $85 \%$ e.e. in acetonitrile. ${ }^{125,126}$

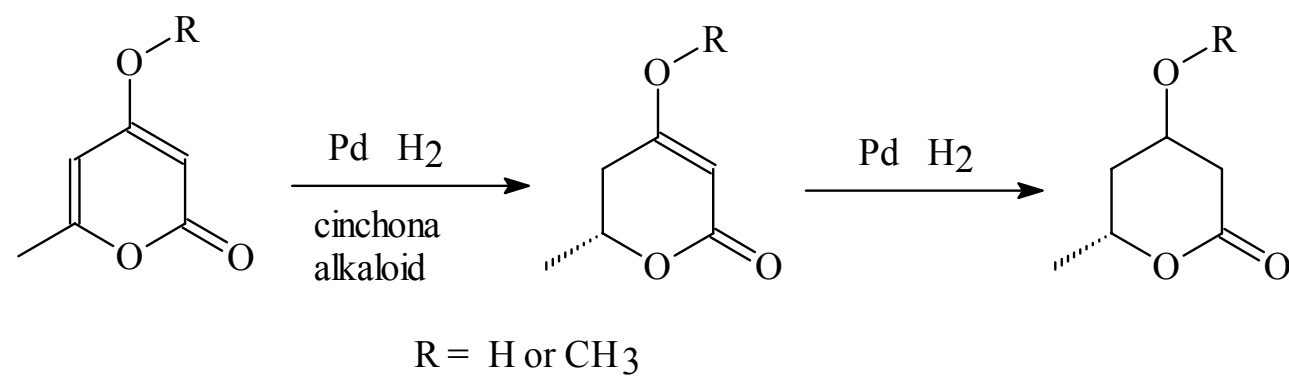

Scheme 8. Enantioselective hydrogenation of pyrone derivatives.

The hydrogenation of 4-methoxy-6-methyl-2-pyrone produced the $(R)$ enantiomer of the dihydropyrone with $94 \%$ e.e. and $95 \%$ chemoselectivity at $80 \%$ conversion over $\mathrm{Pd} / \mathrm{TiO}_{2}$ in the presence of cinchonine. ${ }^{124}$ This is the highest enantioselectivity reported for any enantioselective hydrogenation over chirally modified Pd. A critical point is the low reactant/catalyst or reactant/modifier ratio. $90 \%$ e.e. was achieved with 105 pyrone/CD ratio, but a ratio of 2.1 was necessary to improve the e.e. to $94 \%$.

Another novel use of cinchona-modified Pd is the asymmetric hydrogenation of furan and benzofuran carboxylic acids (scheme 9). ${ }^{127}$<smiles>[Y]c1ccoc1[X]</smiles>

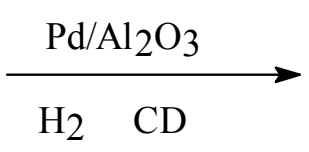<smiles>[X]C1=C([Y])OCC1</smiles>

$\begin{array}{llllll}X & \mathrm{COOH} & \mathrm{COOH} & \mathrm{H} & \mathrm{CH}_{3}\end{array}$ $\mathrm{Y} \quad \mathrm{H} \quad \mathrm{CH}_{3} \quad \mathrm{COOH} \mathrm{COOH}$<smiles>O=C(O)c1cc2ccccc2o1</smiles>

Scheme 9. Enantioselective hydrogenation of furan and benzofuran carboxylic acids.

This catalyst system is moderately effective. $32 \%$ e.e. was achieved at complete conversion of furan-2-carboxylic acid to its tetrahydro derivative and $50 \%$ e.e. at $29 \%$ conversion of benzofuran-2-carboxylic acid to its dihydro derivative. These e.e. values are the highest obtained so far in the asymmetric hydrogenation of furan derivatives. ${ }^{128}$ A major limitation of cinchona modified $\mathrm{Pd}$ is the competing hydrogenation of the alkaloid modifier, necessitating low substrate/modifier ratios (6.5-22). 


\section{Diastereoselective reactions}

\subsection{Reactions of achiral starting compounds}

Achiral tetrasubstituted olefinic compounds, with different substituents on their $\mathrm{sp}^{2}$ carbon atoms, aromatic compounds, with at least two substituents in ortho and meta position, can be hydrogenated forming diastereoisomers.

An instructive example is the hydrogenation of thymol, which is important from an industrial point of view also as results in menthol diastereoisomers (scheme 10):

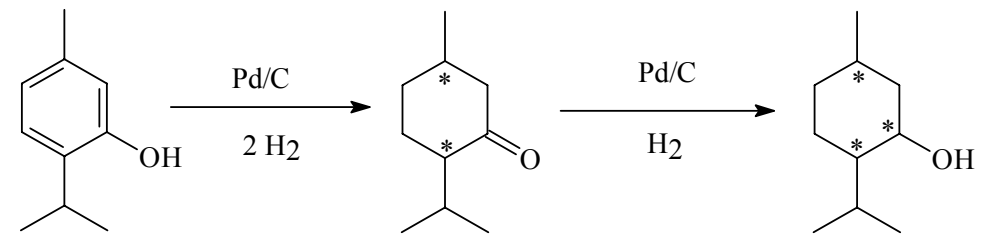

Scheme 10. Hydrogenation of thymol.

Bizhanov et al ${ }^{129}$ summarized the results of the hydrogenation of thymol with different catalysts. The primary goal was the preparation of l-menthol, which had been originally extracted from natural mint containing oils. In gas-phase hydrogenation with a nickel catalyst the menthol diastereoisomers are formed in equilibrium concentration, however in liquid-phase with Pd catalyst among basic conditions higher menthol ratio could be achieved. This is perhaps the basis for the industrial scale production of optically active menthol. ${ }^{130}$

An excellent summary of stereoselective, within this that of diasteroselective hydrogenations can be found in the book of Bartók et al. ${ }^{131}$ Up to now this is the most detailed collection of hydrogenation reactions resulting in diastereomeric compounds.

Recently the hydrogenation of $2,2^{1}$-pyridoin and related compounds was studied in our laboratory. ${ }^{132}$ Why is this reaction discussed in this chapter, when pyridoin has an asymmetric carbon, at least formally?

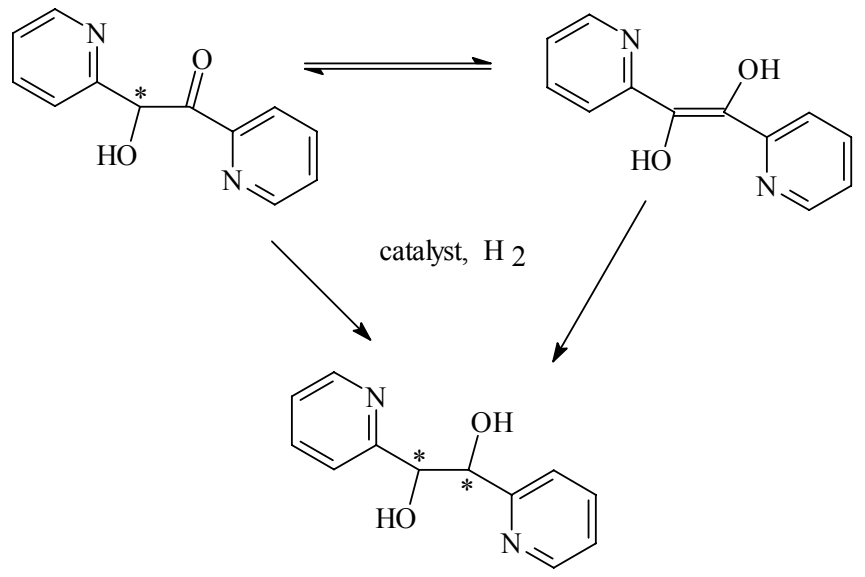

Scheme 11. Hydrogenation of pyridoin.

2,2 ${ }^{1}$-pyridoin has been clearly established as being 1,2-di(2-pyridyl)-1,2-ethenediol by infrared studies. In neutral, acidic, or alkaline solution 2,2 -pyridoin exists to $93-98 \%$ as $1,2-$ 
di(2-pyridyl)-1,2-ethenediol, as proved by titration with Tillmann's reagent. As a matter of fact, in the hydrogenation of 2,2'-pyridoin mainly the saturation of $\mathrm{C}=\mathrm{C}$ double bond occurs, especially with $\mathrm{Pd}$ catalyst. The influence of catalytic metals, catalyst supports, solvents, acid additives, prehydrogenation, and hydrogen pressure on the chemo- and diastereoselectivity was discussed in the hydrogenation of 2,2'-pyridoin. Although hydrogenolysis and ring saturation may occur as side reactions, high chemo- (90-100\%) and moderate diastereoselectivity values were achieved. Over palladium black in an acetonitrile-water solvent mixture, the hydrogenation resulted in a meso/dl ratio of $72 / 28$, while in the hydrogenation over rhodium on carbon the meso/dl ratio was 29/71. The phenomenon of diastereoselection in the hydrogenation was explained by the stereochemistry of the hydrogen addition, considering the cis-trans isomerisation on the catalyst surface, the possible enolisation, and the competing $\mathrm{C}=\mathrm{C}$ and $\mathrm{C}=\mathrm{O}$ reductions.

This hydrogenation also supplied proof, that diastereoselectivity can be tuned by the catalyst and solvent selection, changing parameters, temperature and pressure, as in this reaction both diastereoisomers could be prepared in significant excess.

\subsection{Reactions of chiral starting compounds}

A frequently used method for diastereoselective hydrogenation is the reduction of molecules having a chiral moiety and a prochiral unsaturated part. The chiral moiety is the source of diastereoselectivity caused by asymmetric induction. In an ideal case, after completing the reduction, the chiral moiety can be removed and even regenerated. With the appropriate combination of the chiral synthon, the hydrogenation catalyst and the reaction conditions high optical yields are possible. The important properties of a good synthon, beside strong asymmetric induction, usually accompanied by the small distance between the newly forming and the original asymmetric centre, are easy accessibility, simple removal and regeneration. Optically active compounds, most frequently used as synthons, are carbohydrates, amino acids, hydroxy acids, terpenes and alkaloids.

The induced diastereoselectivity was studied in the saturation of $\mathrm{C}=\mathrm{C}, \mathrm{C}=\mathrm{O}, \mathrm{C}=\mathrm{N}$ bonds, and of aromatic rings, most attention was paid to the preparation of optically active amino acids. In 2003 two reviews were published about diastereoselective hydrogenations written by Kukula and Prins, ${ }^{39}$ and Besson and Pinel. ${ }^{40}$ Here the recent results with possible practical impact will be summarized.

Pan and Sha ${ }^{133}$ successfully hydrogenated methacycline to $\alpha$-doxycycline with a carbon supported $0.4 \% \mathrm{Pd}$ catalyst which was poisoned by tetramethylthiourea-quinoline, the stereoselectivity in this $\mathrm{C}=\mathrm{C}$ hydrogenation, resulting in the methyl group of $\alpha$-position, was $94.5 \%$. In the hydrogenation of methacycline with the usual $\mathrm{Pd}$ on carbon catalyst even chemoselectivity is small, not only the $\mathrm{C}=\mathrm{C}$ saturation, but ring opening also occurs.

Douja et al. ${ }^{134}$ hydrogenated 2-methyl nicotinic acid bound to the pyroglutamate chiral auxiliary with different noble metal catalysts, which yielded $26 \%$ diastereoselectivity. 
Tellers et al. ${ }^{135}$ developed a preparation method for pure Z-enamines and from these they could carry out the hydrogenation with noble metal catalysts into the corresponding $\beta$-amino esters and amides with high diastereoselectivity.

(S)-Proline proved to be an excellent homogeneous chiral catalyst in some reactions, for example the Robinson-type condensation of exocyclic $\alpha, \beta$-unsaturated ketones. It was suggested that this ability could also be used in heterogeneous hydrogenation. It had been tried in the early 80 's, and since then it remained the only method for preparing an optically active product by simple addition of a chiral auxiliary (not modifier!) to the reaction mixture. The hydrogenation of isophorone with $\mathrm{Pd} / \mathrm{C}$ catalyst, in the presence of stoichiometric amount of (S)-proline, in methanol as solvent at room temperature resulted in dihydroisophorone with enantiomeric excesses up to $80 \%$. After the uptake of one mol of hydrogen the chemical yield of dihydroisophorone decreased significantly and the major product was the alkylated proline (scheme 12). ${ }^{136,137}$

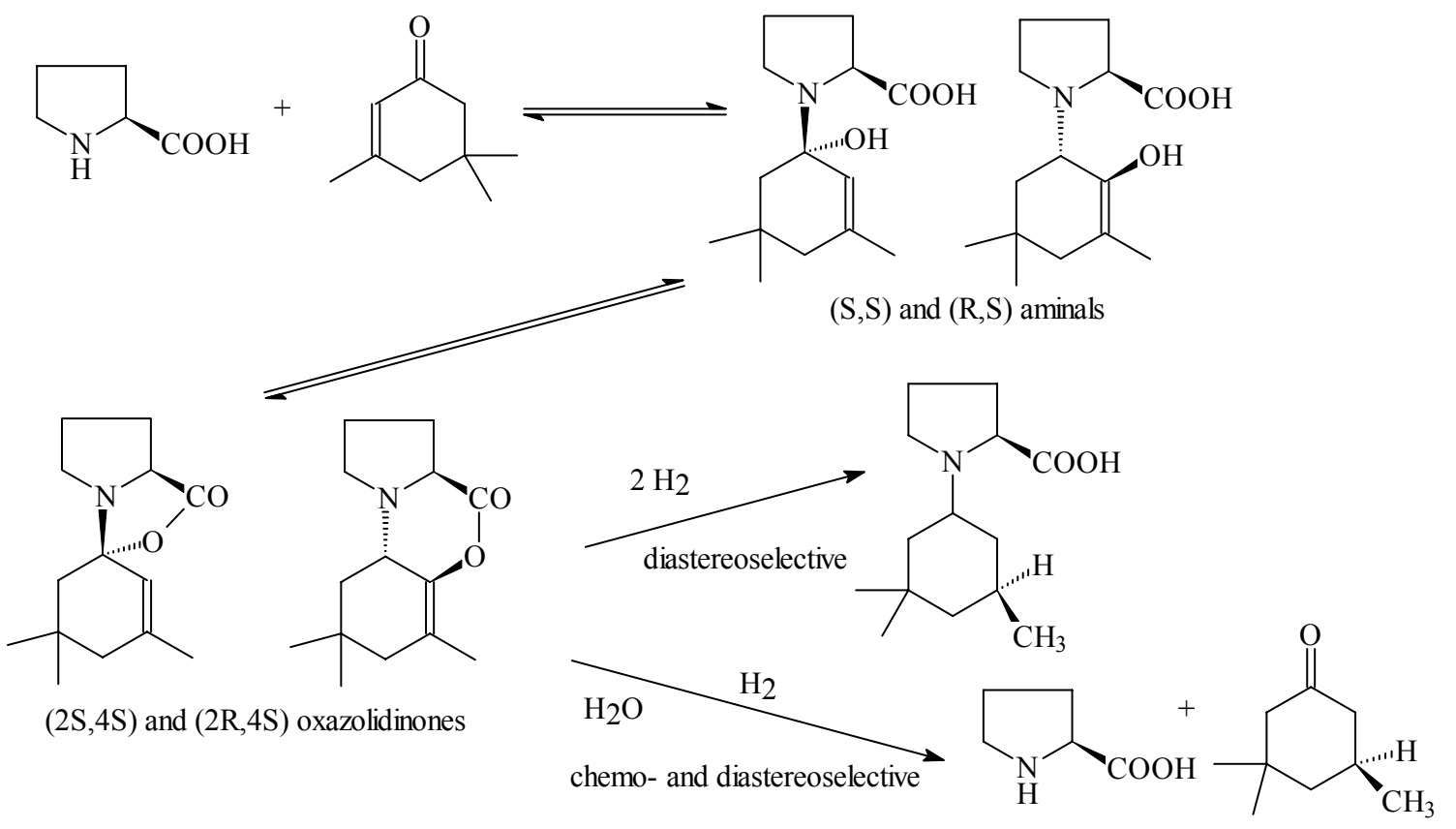

Scheme 12. Asymmetric hydrogenation of isophorone in the presence of (S)-proline.

Recently (S)-proline was also used as a chiral auxiliary in the hydrogenation of exocyclic $\alpha, \beta$-unsaturated ketones with palladium on carbon catalysts, ${ }^{138}$ producing the corresponding saturated ketones with an optical purity up to $20 \%$ (scheme 6).

In the case of the exocyclic $\alpha, \beta$-unsaturated ketones the zwitterionic form of proline gave the addition and/or condensation product probably in lower concentration, therefore chemo- and enantioselectivity was low $(<10 \%)$. In order to increase the reactivity of the $(S)$-proline, sodium methylate $(\mathrm{NaOMe})$ was added to convert the proline into its sodium salt, in the presence of the 
strong base the reduction became chemoselective and gave the saturated ketone in higher optical purity.

The efficiency of the $(S)$-proline chiral auxiliary in the above hydrogenations, both in that of the endo- and exocyclic unsaturated ketones, was limited: the e.e. was low or if it was significant then the chemical yield of the saturated ketone became low because of the reductive alkylation of the (S)-proline. In these asymmetric reactions the hydrogenation step was really diastereoselective, as the reduction of the chiral and simultaneously prochiral condensation intermediates afforded the optically active saturated ketones (after hydrolysis).

About diastereoselective heterogeneous catalytic hydrogenations the following general conclusions can be made:

Diastereoselectivity is determined decisively by the molecular structure of the substrate, the d.e. is larger if the asymmetric center is in a rigid ring and is near to the reducable function.

The d.e. can also be affected if the conversion of the conformers of the substrate is hindered or some of the conformers is stabilized by hydrogen bridges.

The catalytically active metal, the support, the solvent influence the diastereoselectivity, in some cases even the configuration of the product. Usually the d.e. is higher in apolar solvents. The lower is the reaction temperature, the higher can be the diastereoselectivity.

In the hydrogenation of aromatic compounds achiral amines as catalyst modifiers increase the d.e.

The proline moiety proved to be an effective chiral synthon in several reactions.

In that case, if the chiral synthon is easily available, removable, regenerable, the hydrogenation may have a synthetic value even on a larger scale.

\section{Conclusions}

In Table 2 there are collected the characteristics of hydrogenation methods resulting in optically active compounds. In spite of that the chirally modified metal catalysts afford the most elegant solution for this purpose, their research and application is minor in comparison with that of the homogeneous complex catalysts. The reason for this can be that such systems are very rare and specific.

For synthetic application the transition metal complex catalysts, especially in heterogenised form offer a good solution, similarly appropriate methods could be the heterogeneous catalyzed diastereoselective reductions if the chiral synthon is easily regenerable. 


\begin{tabular}{|c|c|c|c|c|c|c|c|}
\hline 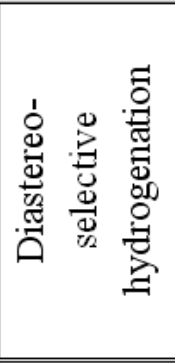 & 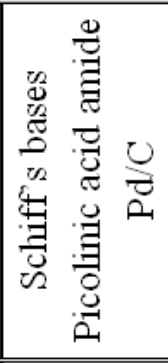 & 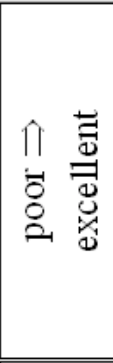 & $\begin{array}{l}\frac{0}{0} \\
\frac{\pi}{2} \\
\frac{\tilde{d}}{0} \\
\text { d }\end{array}$ & 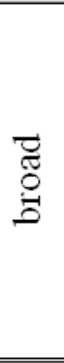 & 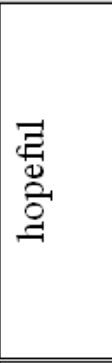 & 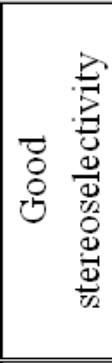 & 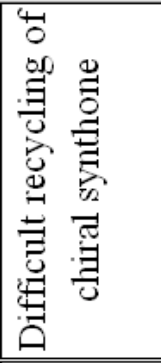 \\
\hline 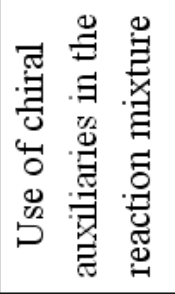 & 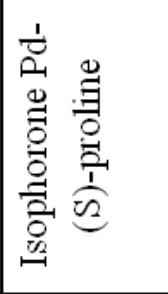 & $\begin{array}{l}\vec{D} \\
0 \\
0\end{array}$ & $\begin{array}{l}\ddot{\circ} \\
\stackrel{0}{0}\end{array}$ & $\begin{array}{l}\text { 总 } \\
\text { 息 }\end{array}$ & $\stackrel{g}{g}$ & 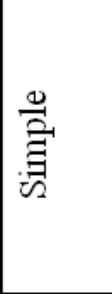 & 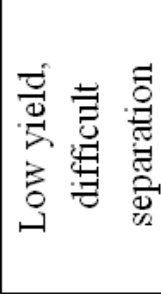 \\
\hline 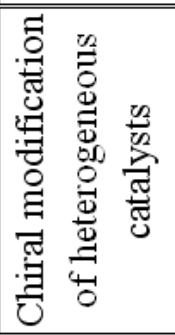 & 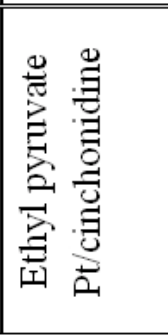 & 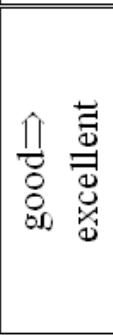 & $\begin{array}{l}\overrightarrow{0} \\
\stackrel{0}{0} \\
\stackrel{0}{0}\end{array}$ & 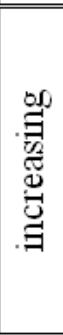 & 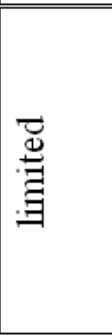 & 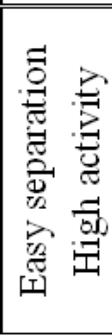 & 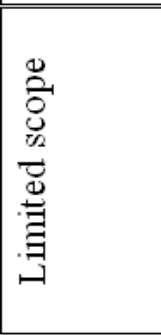 \\
\hline 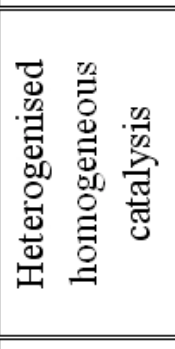 & 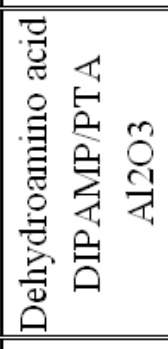 & 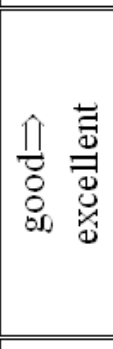 & $\begin{array}{l}\vec{Z} \\
\stackrel{0}{0} \\
0\end{array}$ & 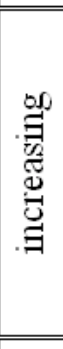 & 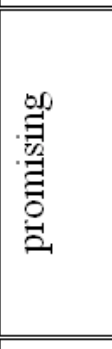 & 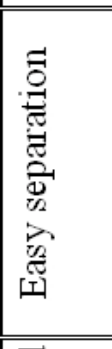 & 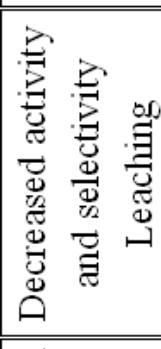 \\
\hline 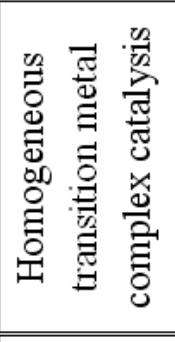 & 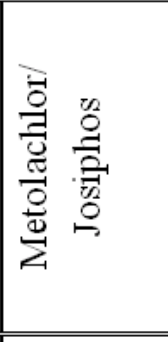 & 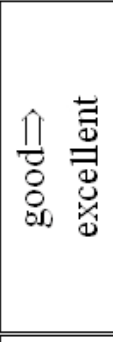 & 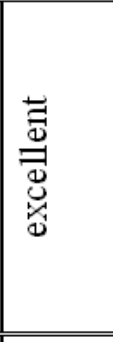 & 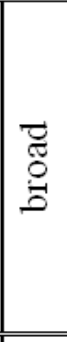 & $\begin{array}{l}\vec{O} \\
\stackrel{0}{0} \\
\stackrel{0}{0}\end{array}$ & 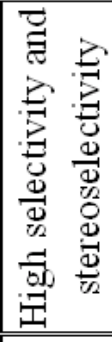 & 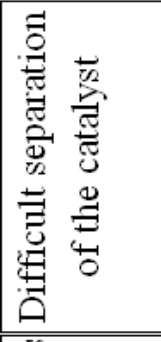 \\
\hline 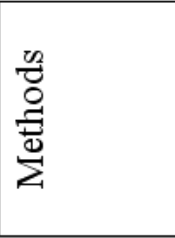 & 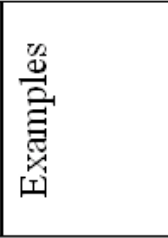 & 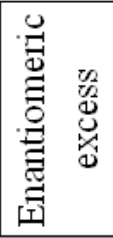 & 苞 & 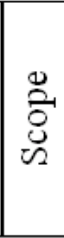 & 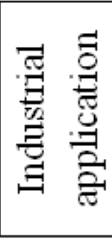 & 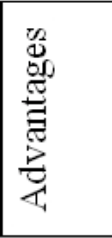 & 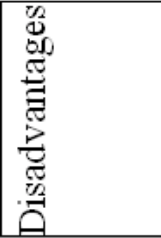 \\
\hline
\end{tabular}




\section{Acknowledgements}

The authors acknowledge the financial support of the Hungarian OTKA Foundation under the contract number T 043153 as well as of the Varga József Foundation.

\section{References}

1. Rylander, P. N. Catalytic Hydrogenation over Platinum Metals; Academic Press: New York, 1967.

2. Freifelder, M. Practical Catalytic Hydrogenation; Wiley-Interscience: New York, 1971.

3. Augustine, R. L. Catalytic Hydrogenation; Dekker: New York, 1965.

4. Rylander, P. N. Catalytic Hydrogenation in Organic Synthesis; Academic Press: New York, 1979.

5. Freifelder, M. Catalytic Hydrogenation in Organic Sythesis, Procedures and Commentary; Wiley: New York, 1978.

6. Cerveny, L. Catalytic Hydrogenation; Elsevier: Amsterdam, 1986.

7. Augustine, R. L. Heterogeneous Catalysis for the Synthetic Chemist; Marcel Dekker: New York, 1996.

8. Polastro, E. Chiral Reactions in Heterogeneous Catalysis, Jannes, G.; Dubois, V., Eds. Plenum Press: NY and London, 1995; pp 5-20.

9. Izumi, Y.; Imaida, M.; Fukawa, H.; Akabori, S. Bull. Chem. Soc. Jpn. 1963, 36, 21.

10. Blaser, H. U.; Spindler, F.; Studer, M. Applied Catalysis A: General 2001, 221, 119.

11. Huck, W.-R.; Mallat, T.; Baiker, A. Catal. Lett. 2002, 80, 87.

12. Kubota, J.; Zaera, F. J. Am. Chem. Soc. 2001, 123, 11115.

13. Ferri, D.; Bürgi, T. J. Am. Chem. Soc. 2001, 123, 12074.

14. Attard, G.A. J. Phys. Chem. B 2001, 105, 3158.

15. Switzer, J.A.; Kothari, H M.; Poizot, P.; Nakanishi, S.; Bohannan, E. W. Nature (London, United Kingdom) 2003, 425, 490.

16. Horvath, J. D.; Gellman, A. J. Topics in Catalysis 2003, 25, 9.

17. Buergi, T. Chimia 2003, 57, 623.

18. Blaser, H. U.; Jalett, H. P.; Müller, M.; Studer, M. Catal. Today 1997, 37, 441.

19. Pfaltz, A.; Heinz, T. Topics Catal. 1997, 4, 229.

20. Tungler, A.; Fodor, K. Catalysis Today 1997, 37, 191.

21. Besson, M.; Pinel, C. Topics Catal. 1998, 5, 25.

22. Wells, P. B.; Wilkinson, A. G. Topics Catal. 1998, 5, 39.

23. Piccolo, O. Chimica e l'Industria 1998, 80, 1177.

24. Brieden, W. Conf. Current Trends in Organic Synth.; Venezia, Kluwer: New York, 1998, p 163. 
25. Blaser, H. U.; Jalett, H. P.; Lottenbach, W.; Studer, M. J. Am. Chem. Soc. 2000, 122, 12675.

26. (a) Tai, A.; Sugimura, T. In Chiral Catalyst Immobilization and Recycling; De Vos, D. E.; Vankelecom, I. F. J.; Jacobs, P. A.; Eds.; Wiley-VCH: Weinheim, 2000; p 173. (b) Baiker, A. ibid. p 155. (c) Wells, P. B.; Wells, P. K. ibid. p 123.

27. Baiker, A. J. Mol. Cat. A: Chemical 2000, 163, 205.

28. Osawa, T.; Harada, T.; Takayasu, O. Topics Catal. 2000, 13, 155.

29. Mallat, T.; Baiker, A. Applied Cat., A: General 2000, 200, 3.

30. Hölderich, W. F.; Wagner, H. H.; Valkenberg, M. H. Special Publ. Royal Soc. of Chem. 2001, 266, 76.

31. Tungler, A.; Fogassy, G. J. Mol. Catal. A, Chemical 2001, 173, 231.

32. von Arx, M.; Mallat, T.; Baiker, A. Topics Catal. 2002, 19, 75.

33. Blaser, H. U.; Pugin, B.; Spindler, F. In Applied Homogeneous Catalysis with Organometallic Compounds; Cornils, B.; Herrmann, W.A.; Eds; 2002; p 601, p 1131, pp 1343-1351.

34. Dwars, T.; Oehme, G. Advanced Synth.\& Cat. 2002, 344, 239.

35. Li, X.; Li, C. Huaxue Jinzhan 2003, 15, 204.

36. Crudden, C. M.; Allen, D. P.; Motorina, I.; Fairgrieve, M. Nanostructured Catalysts 2003, 113.

37. Raval, R. Nanostructured Catalysts 2003, 179.

38. Widegren, J. A.; Finke, R. G. J. Mol. Cat. A: Chemical 2003, 198, 317.

39. Kukula, P.; Prins, R. Topics Catal. 2003, 25, 29.

40. Besson, M.; Pinel, C. Topics Catal. 2003, 25, 43.

41. Studer, M.; Blaser, H.-U.; Exner, C. Adv. Synth. Catal. 2003, 345.

42. Wiebus, E.; Cornils, B. Chem.-Ing. Tech. 1994, 66, 916.

43. Joó, F.; Kathó, A. J. Mol. Catal. A, 1997, 116, 3.

44. Herrmann, W. A.; Kohlpaintner, C. W. Angew. Chem., Int. Ed. 1993, 32, 1524.

45. Kalck, P.; Monteil, F. Adv. Organomet. Chem. 1992, 34, 219.

46. Amrani, Y.; Sinou, D. J. Mol. Catal. 1984, 24, 231.

47. Horváth, I.; Joó, F. Aqueous Organometallic Chemistry and Catalysis; Kluwer: Dordrecht/Boston/London, 1995.

48. Haggin, J. Chem. Eng. News 1994, (Oct. 10) 28.

49. Cornils, B. Nachr. Chem. Tech. Lab. 1994, 42, 1136.

50. Kumar, A.; Oehme, G.; Roque, J. P.; Schwarze, M.; Selke, R. Angew. Chem. Int. Ed. 1994, 33, 2197.

51. Takasago Int. Comp. (Ishizaki, T.; Kumobayashi, H.) EP 0.544.455, 1992.

52. Amrani, Y.; Lecomte, L.; Sinou, D. Organometallics 1989, 8, 542.

53. Nuzzo, R. G.; Haynie, S. L.; Wilson, M. E.; Whitesides, G. M. J. Org. Chem. 1981, 46, 2861.

54. Sinou, D.; Safi, M.; Claver, C.; Masdeu, A. J. Mol. Catal. 1991, 68, L9. 
55. Benhamza, R.; Amrani, Y.; Sinou, D.; J. Organomet. Chem. 1985, 288, C37.

56. Trinkhaus, S.; Kadyrov, R.; Selke, R.; Holz, J.; Götze, L.; Börner, A. J. Mol. Catal. A. 1999, 144, 15.

57. Lensink, C.; Rijnberg, E.; de Vries, J. G. J. Mol. Catal. A. 1997, 116, 199.

58. Malmström, T.; Andersson, C. J. Mol. Catal. A. 2000, 157, 79.

59. Köckritz, A.; Bischoff, S.; Kant, M.; Lücke, B.; Vorlop, K-D.; Prüsse, U.; Morawsky, V.; Ger. Offen. 2002, DE 10112358, 20010308.

60. Tanielyan, S. K.; Augustine, R.L.; Seton Hall University, US Patent, 6,005,148, 1999.

61. Tanielyan, S. K.; Augustine, R. L.; Seton Hall University, US Patent, 6,025,295, 2000.

62. Tanielyan, S. K.; Augustine, R. L.; Chem. Ind.; Dekker, 75, Catalysis of Organic Reactions, 1998, 101.

63. Tanielyan, S. K.; Augustine, R. L.; Anderson, S.; Yang, H.; Gao, Y.; Chem. Ind.; Dekker, 82, Catalysis of Organic Reactions 2000, 497.

64. Reyes, C.; Gao, Y.; Zsigmond, A.; Goel, P.; Mahata, N.; Tanielyan, S. K.; Augustine, R. L.; Chem. Ind.; Dekker, 82, Catalysis of Organic Reactions 2000, 627.

65. Anderson, S.; Yang, H.; Tanielyan, S. K.; Augustine, R. L.; Chem. Ind.; Dekker, 82, Catalysis of Organic Reactions 2000, 557.

66. Goel, P.; Anderson, S.; Nair, J.; Reyes, C.; Gao, G.; Tanielyan, S.K.; Augustine, R.L.; Chem. Ind.; Dekker, 89, Catalysis of Organic Reactions 2003, 523.

67. Blaser, H.-U.; Müller, M. Stud. Surf. Sci. Catal. 1991, 59, 73.

68. Blaser, H.-U.; Tetrahedron: Asymmetry 1991, 2, 843

69. Osawa, T.; Hayashi, Y.; Ozawa, A.; Harada, T.; Takayasu, O. J. Mol. Catal. A 2001, 169, 289.

70. Sugimura, T. Catal. Surv. Jpn. 1999, 3, 37.

71. Osawa, T.; Harada, T.; Takayasu, O. Topics Catal. 2000, 13, 155.

72. Osawa, T.; Harada, T.; Tai, A. Catal. Today 1997, 37, 465.

73. Nakagawa, S.; Sugimura, T.; Tai, A. Chem. Lett. 1997, 859.

74. Nitta, Y. Topics Catal. 2000, 13, 179 ,.

75. Huck, W-R.; Mallat, T.; Baiker, A. J. Catal. 2000, 193, 1.

76. Borszeky, K.; Bürgi, T.; Zhaohui, Z.; Mallat, T.; Baiker, A. J. Catal. 1999, 187, 160.

77. Tungler, A.; Tarnai, T.; Hegedüs, L.; Fodor, K.; Máthé, T. Plat. Met. Rev. 1998, 42, 108.

78. Arx, M.; Mallat, T.; Baiker, A. Topics Catal. 2002, 19, 75.

79. Tai, A.; Imaida, M.; Oda, T.; Watanabe, H. Chem. Lett. 1978, 61.

80. Tai, A.; Morimoto, M. N.; Toshikawam, M.; Uehara, K.; Sugimura, T.; Kikukawa, T. Agric. Biol. Chem. 1990, 54, 1753.

81. Nakahata, M.; Imaida, M.; Ozaki, H.; Harada, T.; Tai, A. Bull. Chem. Soc. Jpn. 1982, 55, 2186.

82. Bakos, J.; Tóth, I.; Marko, L. J. Org. Chem. 1981, 46, 5427.

83. Orito, Y.; Imai, S.; Niwa, S.; Hung, N. G. J. Synth. Org. Chem. 1979, 37, 173.

84. Orito, Y.; Imai, S.; Niwa, S. J. Chem. Soc. Jpn. 1979, 1118. 
85. Orito, Y.; Imai, S.; Niwa, S. J. Chem. Soc. Jpn. 1980, 670.

86. Orito, Y.; Imai, S.; Niwa, S. J. Chem. Soc. Jpn. 1982, 137.

87. Smith, G. V.; Notheisz, F. Heterogenous Catalysis in Organic Chemistry, Academic Press; San Diego, 1999.

88. Wells, P. B.; Simons, K. E.; Slipszenko, J. A.; Griffiths, S. P.; Ewing, D. F. J. Mol. Catal. A 1999, 146, 159.

89. Baiker, A. J. Mol. Catal. A 2000, 163, 205.

90. Török, B.; Balazsik, K.; Szöllösi, G.; Felföldi, K.; Bartók, M. Chirality 1999, 11, 470.

91. Zuo, X.; Liu, H.; Guo, C.; Yang, X. Tetrahedron 1999, 55, 7787.

92. Blaser, H.-U.; Jalett, H.P. Stud. Surf. Sci. Catal. 1993, 78, 139.

93. Wang, G. Z.; Mallat, T.; Baiker, A. Tetrahedron: Asymmetry 1997, 8, 2133.

94. Schürch, M.; Künzle, N.; Mallat, T.; Baiker, A. J. Catal. 1998, 176, 569.

95. Künzle, N.; Szabó, A.; Schürch, M.; Wang, G.; Mallat, T.; Baiker, A. Chem. Commun. 1998, 1377.

96. Studer, M.; Burkhardt, S.; Indolese, A. F.; Blaser, H.-U. Chem. Commun. 2000, 1327.

97. Toukonitty, E.; Mäki-Arvela, P.; Wärna, J.; Salmi, T. Catal. Today 2001, 66, 411.

98. Török, B.;. Felföldi, K; Balazsik, K.; Bartók, M. Chem. Commun. 1999, 1725.

99. Studer, M.; Burkhardt, S.; Blaser, H. U. Chem. Commun. 1999, 1727.

100. Akabori, S.; Sakurai, S.; Izumi, Y.; Fuji, Y. Nature 1956, 178, 323.

101. Terentiev, A.P.; Klabunovskii, E.I.; Patrikeev, V.V. Dokladi Akademii Nauk SSSR. 1989, $74,947$.

102. Tungler, A.; Tarnai, T.; Hegedűs, L.; Fodor, K.; Máthé, T. Plat. Met. Rev. 1998, 42.

103. Baiker, A.; Blaser, H.-U.; In. Handbook of Heterogeneous Catalysis; Ertl, G.; Knözinger H.; Weitkamp J.; Eds; VCH: Weinheim, 1997; p 2422.

104. Hutchings, G. J. Chem. Commun. 1999, 301.

105. Wells, P. B.; Wilkinson, A. G. Topics Catal. 1998, 5, 39.

106. Osawa, T.; Mita, S.; Iwai, A.; Takayasu, O.; Harada, T.; Matsuura, I. Stud. Surf. Sci. Catal. 1998, 118, 313.

107. Tungler, A.; Fogassy, G.; J. Mol. Catal. A 2001, 173, 231.

108. Halpern, J. Asym. Synth. 1985, 5, 1.

109. Kagan, H. B. Bull. Soc. Chim. France 1988, 5, 846.

110. Dang, T. P.; Kagan, H. B. Chem. Commun. 1971, 481.

111. Melillo, G. D.; Larsen, R. D.; Mathre, D. J.; Slukis, W. F.; Wood, A. W.; Colleluori, J. J. Org. Chem. 1987, 52, 5143.

112. Borszeky, K.; Mallat, T.; Baiker, A. Tetrahedron: Asymmetry 1997, 8, 3745.

113. Borszeky, K.; Mallat, T.; Baiker, A. Catal. Lett. 1996, 41, 199.

114. Nitta, Y.; Kobiro, K. Chem. Lett. 1996, 897.

115. Borszeky, K.; Mallat, T.; Baiker, A. Catal. Lett. 1999, 59, 95.

116. Nitta, Y.; Shibata, A. Chem. Lett. 1998, 2, 161.

117. Borszeky, K.; Bürgi, T.; Zhaohui, Z.; Mallat, T.; Baiker, A. J. Catal. 1999, 187, 160. 
118. Blaser, H. U.; Hönig, H.; Studer, M.; Wedemeyer-Exl, C. J. Mol. Catal. A 1999, 139, 253.

119. Thorey, C.; Hénin, F.; Muzart, J. Tetrahedron: Asymmetry 1996, 7, 975.

120. Fogassy, G.; Tungler, A.; Lévai, A. J. Mol. Catal. A 2003, 192, 189.

121. Fogassy, G.; Tungler, A.; Lévai, A.; Tóth, G. J. Mol. Catal. A 2002, 179, 100.

122. Tungler, A.; Máthé, T. Tarnai, T.; Fodor, K.; Tóth, G.; Kajtár, J.; Kolossváry, I.; Herényi, B.; Sheldon, R.A. Tetrahedron: Asymmetry 1995, 6, 2395.

123. Huck, W.-R.; Mallat, T.; Baiker, A. New J. Chem. 2002, 26, 6.

124. Huck, W.-R.; Mallat, T.; Baiker, A. Catal. Lett. 2002, 80, 87.

125. Huck, W.-R.; Mallat, T.; Baiker, A. Catal. Lett. 2000, 69, 129.

126. Huck, W.-R.; Mallat, T.; Baiker, A. J. Catal. 2000, 193, 1.

127. Maris, M.; Huck, W.-R.; Mallat, T.; Baiker, A. J. Catal. 2003, 219, 1, 52.

128. Studer, M.; Wedemeyer-Exl, C.; Spindler, F.; Blaser, H. U. Monatsh. Chem. 2000, 131, 1335.

129. Bizhanov, Z.A.; Imankulov, T. S.; Konuspaev, S. R.; Vestnik Ministerstva Obrazovaniya I Nauki Respubliki Kazakhstan, Natsionalnoi Akademii Nauk Respubliki Kazakhstan 2002, $1,131$.

130. Darsow, G.; Langer, R.; (Bayer AG) Ger. Offen, DE 19718116, 1998.

131. Bartók, M.; Czombos, J.; Felföldi, K.; Gera, L.; Göndös, Á.; Molnár, Á.; Notheisz, F.; Pálinkó, I.; Wittmann, Gy.; Zsigmond, Á.G. Stereochemistry of Heterogeneous Metal Catalysis, Wiley-Interscience: New York, 1985.

132. Háda, V.; Tungler, A.; Szepesy, L. J. Catal. 2002, 209, 472.

133. Pan, Z.; Sha, Y. Applied Cat. A 2003, 252, 347.

134. Douja, N.; Raluca, B.M.; Besson, M.; Pinel, C. Tetrahedron Lett. 2003, 44, 6991.

135. Tellers, D. M.; Ikemoto, N.; Rivera, N.; Dreher, S. D.; Liu, J.; Njolito, E.; Huang, A.; Hsiao, Y.; McWilliams, J. C.; Williams, J. M.; Sun, Y.; Armstrong, J. D.; Mathre, D. J.; Grabowski, E. J. J. Abstract of Papers, 226 ${ }^{\text {th }}$ ACS National Meeting, NY, 2003.

136. Tungler, A.; Kajtár, J.; Máthé, T.; Tóth, G.; Fogassy, E.; Petró, J. Catal. Today 1989, 5, 159.

137. Tungler, A.; Máthé, T.; Petró, J.; Tarnai, T. J. Mol. Catal. A 1990, 61, 259.

138. Fogassy, G.; Tungler, A.; Lévai, A.; Tóth, G. J. Mol. Catal. A 2002, 179, 100. 